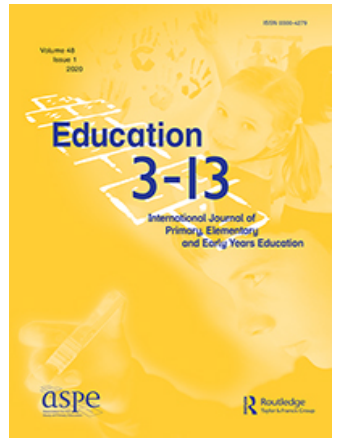

\title{
Education 3-13
}

International Journal of Primary, Elementary and Early Years Education

ISSN: 0300-4279 (Print) 1475-7575 (Online) Journal homepage: https://www.tandfonline.com/loi/rett20

\section{Personal meaning maps as an assessment tool for a Planetarium session: a study with primary school children}

\section{Faria, D. Boaventura \& E. Guilherme}

To cite this article: C. Faria, D. Boaventura \& E. Guilherme (2020) Personal meaning maps as an assessment tool for a Planetarium session: a study with primary school children, Education 3-13, 48:1, 66-75, DOI: $10.1080 / 03004279.2019 .1574855$

To link to this article: https://doi.org/10.1080/03004279.2019.1574855

曲 Published online: 01 Feb 2019.

Submit your article to this journal $๘$

Џll Article views: 250

Q View related articles $\asymp$

View Crossmark data \lceil 


\title{
Personal meaning maps as an assessment tool for a Planetarium session: a study with primary school children
}

\author{
C. Faria (1) ${ }^{\mathrm{a}}$, D. Boaventura ${ }^{\mathrm{b}, \mathrm{c}}$ and E. Guilherme ${ }^{\mathrm{a}}$ \\ anstituto de Educação da Universidade de Lisboa, Alameda da Universidade, Lisbon, Portugal; ${ }^{\text {E}}$ Escola Superior de \\ Educação João de Deus, Lisbon, Portugal; ' ${ }^{\mathrm{M}} \mathrm{MRE}$ - Marine and Environmental Sciences Centre, Laboratório Marítimo \\ da Guia, Faculdade de Ciências da Universidade de Lisboa, Lisboa, Portugal
}

\begin{abstract}
This study aims to analyse the potentialities of using Personal Meaning Maps to assess school children's learning in a visit to a Planetarium. A total of 123 primary students were involved. They were asked to create a PMM, and a drawing, before and after the visit. The results suggest that the visit enhanced the degree to which students generate words and conceptual categories to describe their understanding of the suggested concepts. PMMs seemed to be a good tool to evaluate the impact of the activities on students' ideas about the thematic explored. Drawings helped to understand the main misconceptions.
\end{abstract}

\section{ARTICLE HISTORY}

Received 12 January 2018

Accepted 21 January 2019

\section{KEYWORDS}

Learning assessment; personal meaning maps; primary education; school visits; non-formal education

\section{Introduction}

The involvement in learning experiences outside the school environment has been pointed out as an important learning process for the promotion of high levels of scientific literacy (e.g. Bybee 2001; CoxPeterson et al. 2003; NRC 2011). There is also some evidence that the pedagogical exploration of these out-of-school experiences can contribute to reducing the gap between classroom science and everyday science (e.g. Braund and Reiss 2004; Hein 2006), an essential aspect for promoting students' positive attitudes towards science learning (Earwicker 2008).

Non-formal science education institutions, like science museums (in a broad sense) can make a strong contribution to achieving these goals. Indeed, one of the main mission of these institutions, apart from research and conservation of the scientific heritage, is the promotion of a greater involvement of the general public with science, and, while working with schools is only part of this goal, it is an essential part (ICOM 2007). In order to accomplish this aim, it is crucial to reinforce their collaboration with the formal educational system. By strengthening school science, these institutions can contribute to the creation of a more interested and receptive audience for future and lifelong science learning (Bell et al. 2009; Chin 2004).

Nowadays, there is a general consensus about the importance of using these institutions as a complement to the work performed in school (NRC 2011; OECD 2003, 2006; Osborne and Dillon 2008). However, one of the main barriers to rely on learning science outside the classroom is the difficulty of assessing the degree of learning that occurs in these non-formal environments (Cainey et al. 2012; Rennie and McClafferty 1996). Moreover, according to Bell et al. (2009), many authors have argued that the diversity of non-formal science learning environments further contributes to the difficulties of assessment in these settings. Indeed, one of the main challenges is the development of practical, evidence-centered means for assessing learning outcomes of participants across the range of science learning experiences (Falk and Dierking 2000). 
This study aims to contribute to this discussion, providing some evidence about the potentialities of using Personal Meaning Maps (PMMs) to assess primary school children's learning in a school visit to a Planetarium, namely their understanding about the scientific concepts explored in this sessions.

\section{Theoretical background}

Science Museums are learning environments with unique characteristics that enhance curiosity, motivation and interest in science (Falk and Dierking 2000), which can complement learning in the more formal environment of the school, not only because they provide direct contact with reality, as the opportunity to contextualise knowledge and its evolution in a broader cultural and environmental context (Xanthoudaki 2002). The visit to the museum is currently considered as an educational tool promoting the visitor's recognition and understanding of their cultural heritage, the acquisition of cognitive and historical knowledge, the development of an aesthetic sense and improved understanding of scientific issues (Xanthoudaki 2002). These institutions can thus contribute to the development of a more interested and receptive school public to the lifelong learning of sciences, playing an important role in achieving the goals present in the main international science education reform documents (; NRC 2011; OECD 2003, 2006; Osborne and Dillon 2008).

One of the fundamental aspects that characterise science museums is that they have real objects that arouse curiosity, admiration and the will to manipulate, creating a context that constitutes an adequate starting point for the development of science understanding, based on personal experiences (Falk, Koran, and Dierking 1986; Pedretti 1997).

The main 'touchstone' in museum education recognises that learning in museums enables 'finding a meaning' for visitors, in the sense that this is mediated not only by the objects exhibited and the way they are presented (exhibitions), but also: by the culture, experiences and previous personal knowledge; and by the conditions under which the visit is carried out (Greco 2007; Hein 2006; Hooper-Greenhill 1999). Museum education is thus redefined as a 'meaningful experience,' with the main intention of facilitating visitors' ability to construct their personal meanings (from what they observe, feel, experience, talk about).

However, is exactly this aspect that makes the assessment of these experiences a very hard task. Bell et al. (2009) tried to signalise some of the characteristics of a visit to these non-formal settings, which makes them difficult to assess. Visits to museums are typically short and isolated, making it problematic to separate the effects of a single visit from the confluence of factors contributing to positive science learning outcomes. The premise of engaging learners in activities largely for the purposes of promoting future learning experiences, beyond the immediate environment, runs counter to the prevalent model of assessing learning on the basis of a well-defined educational treatment (e.g. a lesson). In addition, to a large extent, informal environments are learner-centered, specifically because the agenda is mutually set across participants, making it difficult to consistently control the exposure of participants in the setting to particular treatments, interventions, or activities (Bell et al. 2009).

Probably because of all these constraints, the evaluation of school trips' effectiveness on the learning process is rarely made, or it is made in a too simplistic way (Kisiel 2005). However, there are some empirical studies that provide examples of possible instruments that may be useful to teachers for student learning assessments during school trips, including concept maps (Anderson, Lucas, and Ginns 2003), surveys (Orion et al. 1997), and interviews (Faria, Pereira, and Chagas 2012).

Currently, there are several graphing techniques, including mind maps, that are known to be used in studies related to perceptions and learning development in museums. The mind maps, created in the 70's by Tony Buzan, are highly organised diagrams that encourage learning through the visualisation process (Buzan 2005), allowing to organise ideas, thoughts and knowledge in a similar way as in human brain functioning (Brinkmann 2003; Buzan 2005). Mind maps have the following characteristics: from a central term or concept there is a structure with links and relations between other terms 
or concepts; words, pictures or symbols may be used; the connections and sub-connections that are established can be realised by curved lines and using colours (Buzan 2005).

Mind maps are based on some theoretical educational foundations, namely constructivist theories about learning (Evrekli, Inel, and Balım 2010), that defend the importance of giving the individual an active role in the process of its own learning. While developing their mind map, students will use their prior knowledge to construct new knowledge, establishing relationships between this new knowledge and the existing knowledge in their memory. In this way, mind maps can contribute to the development of the capacity to learn in an active and autonomous way.

The use of mind maps in the learning process has been subject to varied empirical studies, some of which provided evidence of its potential for the development of some skills, such as conceptual knowledge (D'Antoni et al. 2010; Dhindsa, Makarimi-Kasim, and Anderson 2011), improvement of concepts understanding ability and their relationships (Dhindsa, Makarimi-Kasim, and Anderson 2011), of creativity and critical thinking (Kokotovic 2008), as well the identification of students' conceptions (Karatekin 2013).

However, some studies centred on the opinions of teachers and students about the use of mind maps present divergent results. In the case of the study carried out by Evrekli, Balim, and Inel (2009), there are positive opinions on the part of teachers, namely on the effectiveness of mind maps for learning scientific concepts and relationships among them, as well as to foster active learning, and the ability to communicate ideas and motivation for learning. On the other hand, in the study by Zip, Maher, and D'Antoni (2009) the opinions of the students seem to demonstrate that they did not recognise the potentialities of the mind maps as tools of learning and organisation of knowledge.

The Personal Meaning Map (PMM) is a qualitative technique derived from the mind maps, proposed by Falk and Dierking (1992), which evaluates the effects on learning of a particular experience, usually a visit to an exhibition or a museum. The PMM was designed to measure how a specific learning experience uniquely affects the understanding and construction of meaning of each individual, by focusing on their 'experiences, perspectives and histories' (Ritchie and Lewis 2003), thus privileges their constructed realities. Moreover, it does not assume that all learning subjects enter with comparable knowledge or experience nor does it require to produce a specific 'right' response in order to demonstrate learning, thus fitting into the environment characteristics of museums, which enhances personal learning.

Therefore, PMMs can be a particularly useful tool to assess students' learning, (Willis and Miertschin 2006), ensuring that students have prior knowledge on their construction, in nonformal learning contexts such as field trips to museums.

\section{Methodology}

A total of 123 students, between 8 and 10 years old, from eight classes of the primary school (four of the 2nd grade and four of the 4th grade), participated in this study. These students were asked to create a PMM before the visit (pre-visit PMM). At the beginning of the activity, there was a small session where one example of PMM was shown to students, together with a basic explanation on the use of this technique. Students were asked to write (or draw) on an empty page, only with a key-word in the centre (prime), all the ideas that occur to them from this word. After, they participated in a school trip to a Planetarium, assisting to a session about the solar system, focused on the origin of the solar system, and the existence of stars, constellations, planets, nebulae, and galaxies, on the relation between the Earth and the Moon, lunar phases and the seasons of the year. After the end of the session, they were asked to create a second PMM (post-visit PMM). In the post-visit session, students were asked to create a new PMM and not to reformulate the one already created in the pre-visit session. The two key-words used were 'Solar system' (88 students) and 'Moon' (35 students).

As a complement to the PMM, students were also asked to make a drawing related to the study topic at the beginning of the activity and to make a new drawing in order to complete the previous one, at the end of the session. 
Both PMMs and drawings were subject to content analysis. Concerning the PMMs, in a first step, a qualitative analysis was made, taking into account the:

(i) Diversity of the concepts and of the conceptual categories used. The concepts were classified considering their relation with the prime used (directly related, indirectly related and not related).

(ii) Complexity of the PMMs, through the analysis of the associations and ramifications present.

Secondly, the degree of change was calculated by comparing the pre-visit PMM with the post-visit one, taking into account the following dimensions (Falk and Dierking 1992):

(1) Vocabulary extension, which refers to changes in the number of 'appropriate concepts', i.e. concepts directed related and undirected related to the prime, that the individual uses to describe the prime before and after the visit;

(2) Range of concepts used, which refers to changes in the number of conceptual categories used by the student to describe the prime;

(3) Complexity, which refers to the overall understanding about the prime suggested.

For these three dimensions, some indexes were calculated. For the elaboration of the indexes extension and range of each PMM, the number of concepts (directly and indirectly related) and of conceptual categories was counted, respectively, and the percentage of change that occurred from the pre to the post-visit was calculated. In the case of the third dimension, complexity, the number of associations and ramifications present were counted, and the percentage of change that occurred from the pre to the post-visit was calculated.

It was investigated whether the mean degree of change of each index (extension, amplitude, complexity) was significantly different from zero (that is, it was tested if there was any change) using the tstudent test for paired samples.

The drawings were analysed based on a qualitative evaluation, based on the number of concepts presented before and after the visit, and the nature of the errors corrected after the visit.

\section{Results}

\section{PMMs analysis}

In the analysis of the diversity of the concepts, in the prime 'Solar system' the concepts most used by students, both pre-test and post-test, were words associated with planets and celestial bodies. The concepts most used by students in the prime 'Moon' were craters, rocket/spacecraft, phases of the moon and night.

From the comparison of both PMMs, and considering the total sample (123 students), 100 students $(81 \%)$ used new concepts in the post-PMM. However, concerning the concepts directly related with the prime, in the post-PMM, only 51 students (42\%) increased its number, 31 (25\%) maintained the same number, and 41 (33\%) decreased the concepts directed related (from pre-PMM).

The new concepts, directly related with the theme, most used by students with the prime 'Solar system' were Moon (7\%), rocket/spacecraft (7\%), comets (5\%), and satellites (5\%). Concerning the prime 'Moon', the most frequent new concepts were rockets (28\%), astronaut (24\%), craters (17\%) and satellites (13\%).

Regarding the number of concepts indirectly related to the main theme, 62 students (50\%) increased the number of concepts, 38 students (31\%) maintained the same number, and 23 students (19\%) decreased, in comparison with the pre-PMM.

The most frequent new concepts indirectly related present in the post-PMM were: constellations (59\%), stars (10\%), phases of the moon (10\%) and black holes (8\%) for the prime 'Solar System'; and shimmering/bright/luminous (31\%) and ice (23\%) for the prime 'Moon'. 


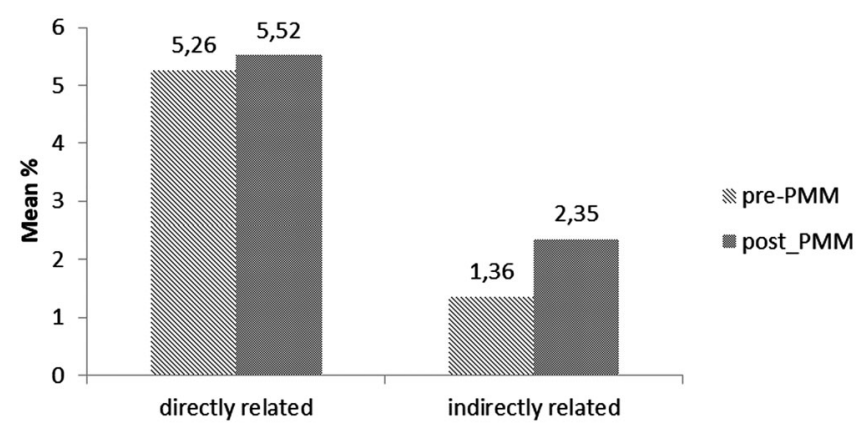

Figure 1. Mean $\%$ of the number of concepts directly and indirectly related with the prime used, in both PMMs (Vocabulary Extension Indexes).

Finally, with regard to the number of concepts not related to the theme (such as water, sea, light), 28 students $(23 \%)$ showed an increase in the post-PMM, and 64 students (52\%) decreased this number.

Regarding the indexes related with the vocabulary extension, in Figure 1 the mean \% of the number of concepts (directly and indirectly related) for each PMM is presented. It can be seen that both indexes are higher in post-PMM, that is, in general, the number of concepts used increased from pre-PMM to post-PMM.

The analysis of the diversity of the conceptual categories revealed that the categories present in the PMMs, in descending order of representativeness, were: Celestial bodies; Formation of the solar system; Human exploration; Moon and Earth Relationship; Moon Characteristics. There was a considerable increase in the concepts present in all categories in post-PMM, with the exception of the Celestial Bodies category.

From the comparison of both PMMs, in $62 \%$ of the post-PMMs ( $n=76$ students) there was an increase in the diversity of concepts, in $29 \%$ ( $n=36$ students) the number of categories represented was maintained from pre-PMM to post-PMM, and in $9 \%(n=11$ students) of the post-PMM this number diminished.

Regarding the index related with the range of concepts (Figure 2), it can be seen that this index range is higher in post-PMM, that is, in general, the number of categories used increased from prePMM to post-PMM.

Finally, in terms of the overall analysis of the complexity of the PMMs, the total associations and relevant associations (i.e. associations related with the theme) were analysed. From the comparison of

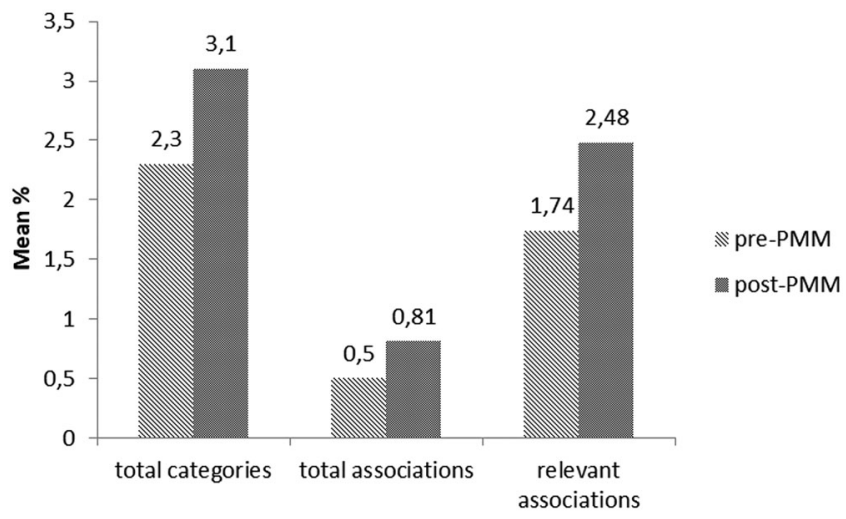

Figure 2. Mean \% of the number of categories, total associations, and relevant word associations present in both PMMs (Range of Concepts and Complexity Indexes). 


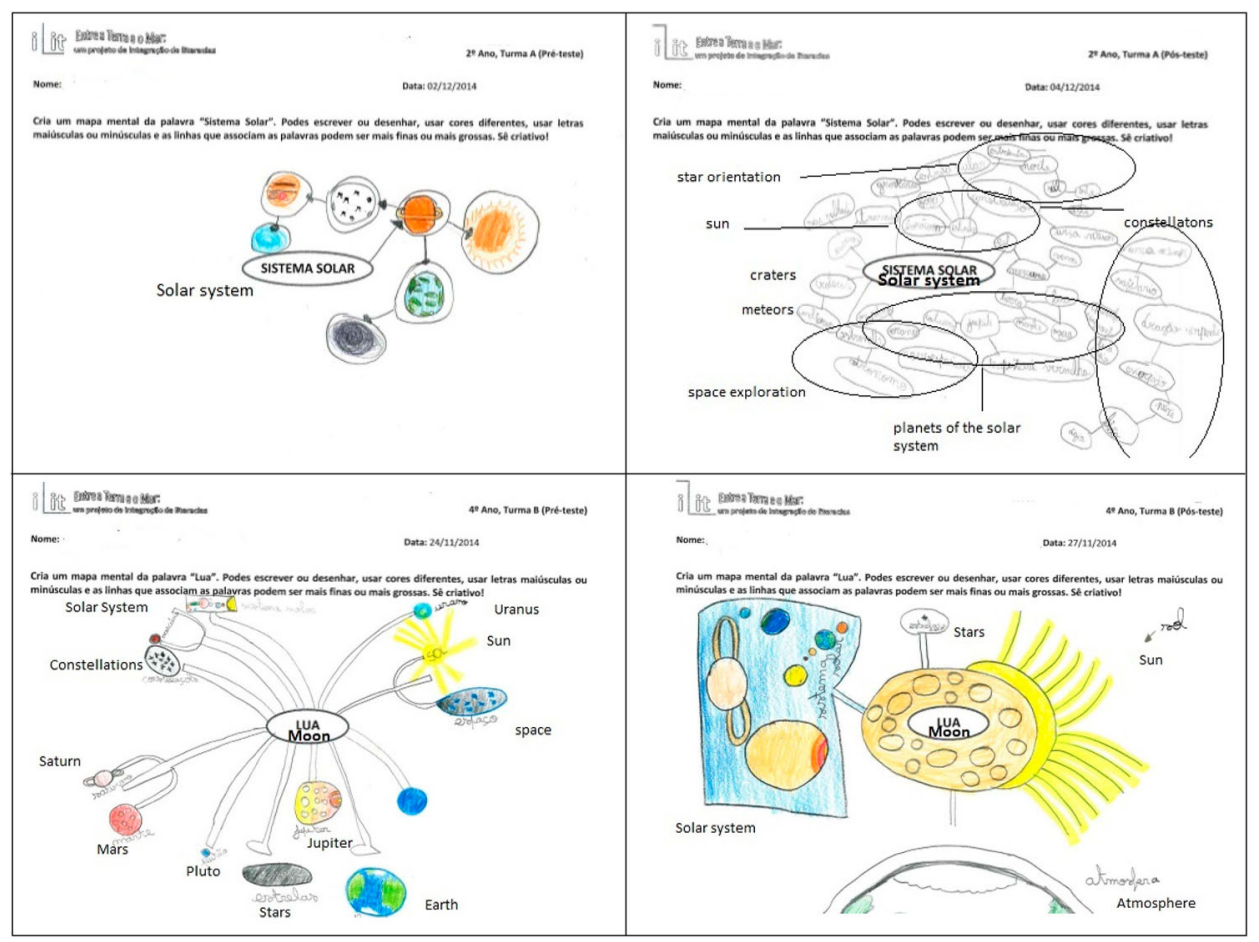

Figure 3. Examples of a pre-PMM (left side of the image) and a post-PMM (right side of the image) of a student of the 2 nd grade (first line) and of the 4th grade (second line).

both PMMs, in the pre-PMM, there were 23 students (19\%) that created associations between the used concepts, and in the post-PMM, there were 25 students (21\%). As for relevant associations there was a slight increase from $44 \%$ in the pre-PMM to $46 \%$ in post-PMM. Regarding the complexity indexes (Figure 2), it can be seen that the both indexes created for the total associations and the relevant associations are higher in post-PMM, which illustrates the greater complexity of the PMMs after the visit (post-PMM). There was also revealed by the high number of branches (within each association) present in post-PMM (see Figure 3 for an example). Indeed, this number increased from one, in the pre-PMM, to 13 in the post-PPM (10\% increase).

The associations most used are related to the:

- Sun: connections with the planets constituent of the Solar System; with other stars; with light, heat and fire.

- Earth: connections with water, air, life, continents; connections to the Moon, to the Sun, and to other planets.

- Spacecrafts: connected to astronauts.

- Moon: connections with craters; phases of the Moon; with the words night, dust; with Earth and Sun.

- Stars: connections with constellations; the Sun; galaxies; some physical characteristics like white colour, brightness; some words like fire and light.

From statistical analysis (Table 1), it can be seen that although the differences in the number of related concepts are not statistically significant $(a<0.05)$, the increase observed in post-PMM in terms of the number of indirectly related concepts is statistically significant $(a<0.001)$. On the 
Table 1 . Results of the T-Test for related samples. $D R=$ directed related; $I R=$ indirected related; $R=$ relevant.

\begin{tabular}{llccc}
\hline & & $\mathrm{T}$ & $\mathrm{df}$ & Sig. (2-tailed) \\
\hline Pair 1 & $\begin{array}{l}\text { Pre_PMM-concepts(DR) } \\
\text { Pair } 2\end{array}$ & -1.046 & 123 & .298 \\
Pair 9 & $\begin{array}{l}\text { Post_PMM-concepts (DR) } \\
\text { Pre_PMM-concepts (IR) }\end{array}$ & -4.941 & 123 & .000 \\
Pair 10 10 & $\begin{array}{l}\text { Pre_PMM-concepts (IR) } \\
\text { Post_PMM-categories }\end{array}$ & -8.080 & 122 & .000 \\
Pair 11 & $\begin{array}{l}\text { Pre_PMM-Associations } \\
\text { Post_PMM-Associations }\end{array}$ & -2.149 & 122 & .034 \\
& $\begin{array}{l}\text { Pre_PMM-Association (R) } \\
\text { Post_PMM-associations(R) }\end{array}$ & -3.036 & 19 & .007 \\
\hline
\end{tabular}

other hand, there are also statistical differences in the total number of categories $(a<0.001)$, total number of associations $(a<0.05)$, and total number of relevant associations (related to the subject) $(a<0.01)$, with an increase in post-PMM.

In conclusion, there is an enrichment of Post-PMM in diversity (number of concepts and categories) and complexity (number of associations and branches).

\section{Drawing analysis}

Drawings analysis related to the prime 'Solar system' revealed that 90\% represent celestial corps, 33\% stars and constellations, and $48 \%$ the solar system (which usually included the planets, sun and moon). All drawings related with the prime 'Moon' presented the phases of the moon.

Considering all sample $(n=123)$, there is an improvement from the pre- to post-drawings of 49 students (34\%). From these, it was observed that 30 students were able to introduce new elements in their drawings, and 21 were able to correct the errors made in the first drawing. In Figure 4, there are two examples of the corrections made: in the drawing of the 2nd grade, the student added the detail of the moon in rotation around the earth in the second drawing; in the one of the 4th grade, the student added the detail of the movement of the planets around the sun (Figure 4). The drawings of the remaining students did not relate to the subject under analysis, were unable to correct the mistakes of the first drawing, or make very similar drawings in both moments (pre- and post-activity).

Concerning the main errors detected, in the drawings related with the prime 'Solar system', are:

- Incorrect ordering of the planets and /or alignment of the planets in the same orbit;

- Dimension and unrealistic characterisation of the planets (the sun often appeared smaller than the planets, the Earth appeared larger than all other planets);

- Existence of planets, other than Saturn, with a set of rings around it (Ex: Mercury);

- The asteroid waist was represented in the wrong place (Ex: between Earth and Mars);

- The moon appears in another point of the Solar system, not nearby Earth, and when correctly placed, it generally presents a much larger dimension;

Concerning the prime 'Moon', the main errors are:

- Incorrect order of the Moon phases;

- Phases of the Moon not well represented and/or identified.

\section{Discussion}

The analysis of the PMMs and drawings examined the impact of the visit on students, and it provided evidence that suggests that the visit enhanced the degree to which the students could use appropriate and diverse vocabulary, generate words and conceptual categories to describe their understanding of the suggested concepts. This is an important finding. 


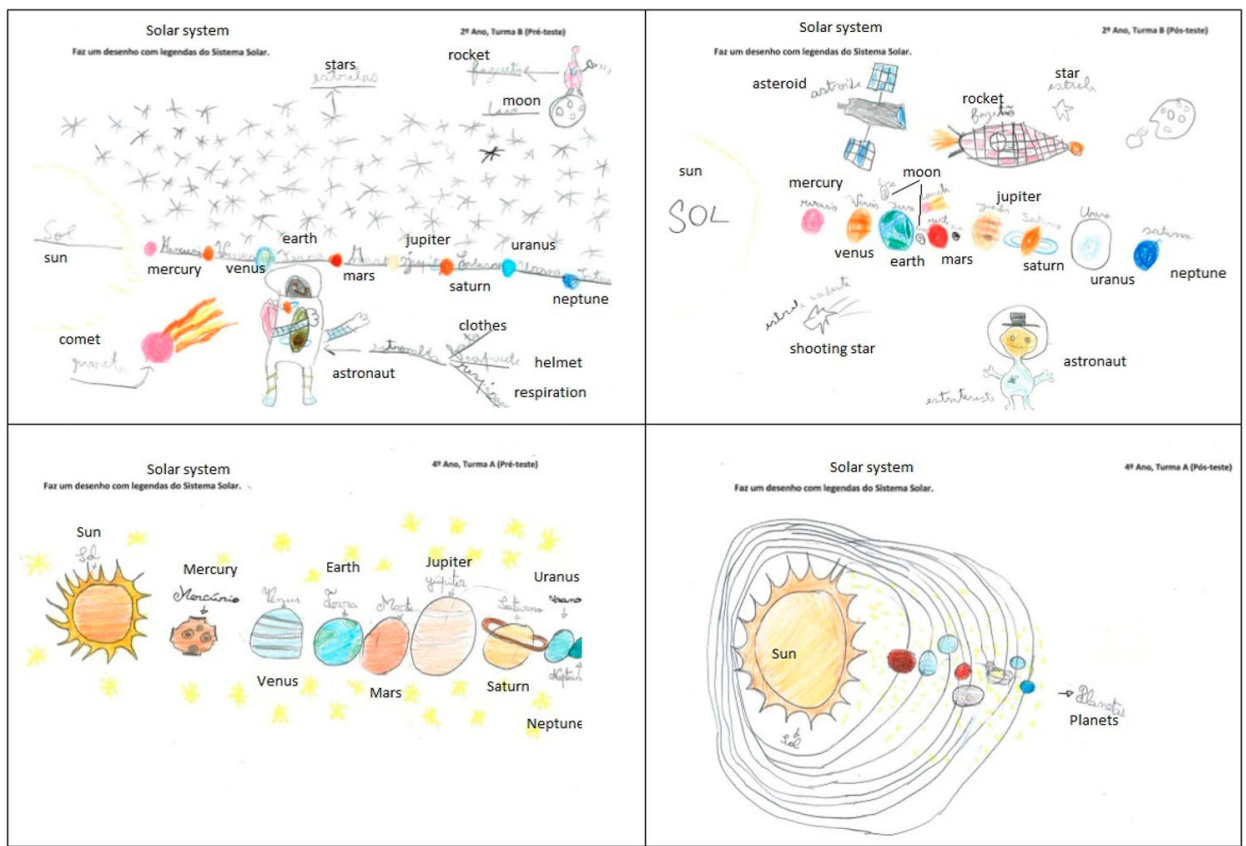

Figure 4. Examples of a pre-drawing (left side of the image) and a post-drawing (right side of the image) of a student of the 2nd grade (first line) and of the 4th grade (second line).

Our results indicate also that drawings can act as a promising assessment tool in these situations. Drawing is one effective way for young children attempting to record their observations, and they can retain more of what they learn in an observation when they draw vs. when they do not (Fox and Lee 2013).

Based on obtained results, it seems that PMMs are good tools to evaluate the impact of activities performed outside the classroom on students' ideas about the thematic explored, at least at primary school levels. It was possible to compare prior and posterior vocabulary, concepts, associations and branches. This conclusion was also referred in another study with small children that aimed to understand how primary school students engage in a scientific research, developed on a natural wetland area (out-of-school context), also using PMMs as an assessment instrument (Jesus-Leibovitz et al. 2017). Drawings, on the other side, can act as a complement of the PMM, helping to understand some of the main misconceptions of children considering the thematic understudy, revealed by the main errors observed.

According to Bell et al. (2009), the traditional method for measuring learning in these non-formal contexts has been to ask textbook-like questions and to judge the nearness of an individual's answer to the expert's version of the scientific story. An essential element of non-formal environments is that learners have some choice in what they attend to, what they take away from an experience, what connections they make to their own lives. Consequently, testing students only on recall of knowledge can cause researchers to miss key learning outcomes for any particular learner, since these outcomes are based on the learner's own experience and prior knowledge.

One of the advantages of PMMs, when compared to other techniques used in learning assessment, is that it is not necessary to assume that the knowledge and experiences of the different persons are a priori comparable. In a PMM, this assumption is irrelevant, since what is measured is the change induced by a given experience in each subject. They allow individuals to express their own personal understandings and generate their own description of an idea. Another advantage 
relates to the fact that PMMs allows children the freedom to express their knowledge without limitations of language and without the imposition of question-defined boundaries.

This is a major result, since there is an urgent need to develop practical and efficient tools to assess this type of learning. The PMM analysis could show the progression of students towards concepts' understanding and help to diagnose student's previous ideas on a particular subject. One interesting way to complement the analysis of these data would be to promote the confrontation of both PMMs (pre and post) by each student, to deeply understand the changes undergone by them. However, there are also some limitations to the use of PMMs as an assessment tool. The great disadvantages of PMMs include the type of links that may be limited to simple associations, the absence of clear links between ideas, and sometimes the difficulty and the time spent in its analysis (Davies 2011).

\section{Disclosure statement}

No potential conflict of interest was reported by the authors.

\section{Funding}

This work was supported by a research project 'Between tide marks: integrating literacies (iLit)' (PTDC/CPE-CED/117923/ 2010) funded by (Fundação para a Ciência e a Tecnologia [FCT]).

\section{ORCID}

C. Faria (D) http://orcid.org/0000-0003-1278-8061

\section{References}

Anderson, D., K. Lucas, and I. S. Ginns. 2003. "Theoretical Perspectives on Learning in an Informal Setting." Journal of Research in Science Teaching 40 (2): 177-199.

Bell, P., B. Lewenstein, A. Shouse, and M. A. Feder. 2009. Learning Science in Informal Environments: People, Places and Pursuits. Committee on Learning Science in Informal Environments, National Research Council. Washington, DC: National Academies Press.

Braund, M., and M. Reiss. 2004. Learning Science Outside the Classroom. New York: Routledge Falmer.

Brinkmann, A. 2003. "Graphical Knowledge Display-Mind Mapping and Concept Mapping as Efficient Tools in Mathematics Education." Mathematics Education Review 16: 35-48.

Buzan, T. 2005. Mind Map: The Ultimate Thinking Tool. London: Thorsons.

Bybee, R. W. 2001. "Achieving Scientific Literacy: Strategies for Ensuring That Free-Choice Science Education Complements National Formal Science Education Efforts." In Free Choice Science Education, how we Learn Science Outside of School, edited by J. H. Falk, 44-63. New York: Teachers College Press.

Cainey, J., R. Bowker, L. Humphrey, and N. Murray. 2012. "Assessing Informal Learning in an Aquarium Using pre- and Post-Visit Drawings." Educational Research and Evaluation 18 (3): 265-281.

Chin, C.-C. 2004. "Museum Experience - a Resource for Science Teacher Education." International Journal of Science and Mathematics Education 2: 63-90.

Cox-Peterson, A. M., D. D. Marsh, J. Kisiel, and L. M. Melber. 2003. "Investigation of Guided School Tours, Student Learning, and Science Reform Recommendations at a Museum of Natural History." Journal of Research in Science Teaching 40 (2): 200-218.

D'Antoni, A. V., G. P. Zipp, V. G. Olson, and T. F. Cahill. 2010. “Does the Mind map Learning Strategy Facilitate Information Retrieval and Critical Thinking in Medical Students?" BMC Med Education 16: 10-61.

Davies, M. 2011. "Concept Mapping, Mind Mapping and Argument Mapping: What are the Differences and do They Matter?" Higher Education 62 (3): 279-301.

Dhindsa, H. S., Makarimi-Kasim, and O. R. Anderson. 2011. "Constructivist-Visual Mind Map Teaching Approach and the Quality of Students' Cognitive Structures". Journal of Science Education and Technology 20 (2): 186-200.

Earwicker, M. J. 2008. "Inspiring the Future: the Role of Informal Learning." School Science Review 89 (329): 37-42.

Evrekli, E., A. G. Balim, and D. Inel. 2009. "Mind Mapping Applications in Special Teaching Methods Courses for Science Teacher Candidates and Teacher Candidates' Opinions Concerning the Applications." Procedia - Social and Behavioral Sciences 1: 2274-2279. 
Evrekli, E., D. Inel, and A. G. Balım. 2010. "Development of a Scoring System to Assess Mind Maps." Procedia - Social and Behavioral Sciences 2 (2): 2330-2334.

Falk, J. H., and L. Dierking. 1992. The Museum Experience. Washington, DC: Whalesback.

Falk, J. H., and L. D. Dierking. 2000. Learning From Museums: Visitors Experiences and Their Making of Meaning. Walnut Creek, CA: Altamira Press.

Falk, J. H., J. J. J. Koran, and L. D. Dierking. 1986. "The Things of Science: Assessing the Learning Potential of Science Museums." Science Education 70 (5): 503-508.

Faria, C., G. Pereira, and I. Chagas. 2012. “D. Carlos de Bragança, a Pioneer of Experimental Marine Oceanography: Filling the Gap Between Formal and Informal Science Education." Science \& Education 21 (6): 813-826.

Fox, J., and J. Lee. 2013. "When Children Draw vs When Children Don't: Exploring the Effects of Observational Drawing in Science." Creative Education 04 (7): 11-14.

Greco, P. 2007. "Science Museums in a Knowledge-Based Society." Journal of Science Communication 6 (2): 1-3.

Hein, G. E. 2006. "Museum Education." In A Companion to Museum Studies, edited by S. MacDonald, 340-352. London: Blackwell Publishing.

Hooper-Greenhill, E. 1999. The Educational Role of the Museum. London: Routledge.

International Commission of Museums [ICOM]. 2007. ICOM definition of a museum. Retrieved in June 2017, from http:// icom.museum/definition.html.

Jesus-Leibovitz, L., C. Faria, A. M. Baioa, and R. Borges. 2017. “ Exploring Marine Biodiversity Through Inquiry with Elementary School Students: A Successful Journey?" Education 3-13: International Journal of Primary, Elementary and Early Years Education 45 (4): 437-449.

Karatekin, K. 2013. "Perception of Environmental Problem in Elementary Students' Mind Maps." Procedia - Social and Behavioral Sciences 93: 868-872.

Kisiel, J. 2005. "Understanding Elementary Teacher Motivations for Science Fieldtrips." Science Education 89 (6): $936-955$.

Kokotovic, V. 2008. "Problem Analysis and Thinking Tools: an Empirical Study of non-Hierarchical Mind Mapping." Design Studies 29 (1): 49-69.

National Research Council [NRC]. 2011. A Framework for Science Education. Washington, DC: National Academy Press.

Organisation for Economic Cooperation and Development [OECD]. 2003. The PISA 2003 Assessment FrameworkMathematics, Reading, Science and Problem Solving Knowledge and Skills (Final Report). Paris: OECD.

Organisation for Economic Cooperation and Development [OECD]. 2006. Evolution of Student Interest in Science and Technology Studies (Policy Report). Paris: OECD.

Orion, N., A. Hofstein, P. Tamir, and G. Giddings. 1997. “Development and Validation of an Instrument for Assessing the Learning Environment of Outdoor Science Activities." Science Education 81: 161-171.

Osborne, J., and J. Dillon. 2008. Science Education in Europe: Critical Reflections. London: King's College London.

Pedretti, E. 1997. "Septic Tank Crisis: A Case Study of Science, Technology and Society Education in an Elementary School." International Journal of Science Education 19 (10): 1211-1230.

Rennie, L. J., and T. P. McClafferty. 1996. "Science Centres and Science Learning." Studies in Science Education 27: $53-98$. Ritchie, J., and J. Lewis. 2003. Qualitative Research Practice: A Guide for Social Science Students and Researchers. London: Sage.

Willis, C. L., and S. L. Miertschin. 2006. "Mind Maps as Active Learning Tools." Journal of Computing Sciences in Colleges Archive 21 (4): 266-272.

Xanthoudaki, M. 2002. "Introduction." In A Place to Discover: Teaching Science and Technology with Museums, edited by M. Xanthoudaki, 5-13. Milão: Museo Nazionale della Scienza e della Tecnologia 'Leonardo da Vinci' and Socrates programme of the European Union.

Zip, G. P., C. Maher, and A. V. D’Antoni. 2009. "Mind Maps: Useful Schematic Tool For Organizing And Integrating Concepts Of Complex Patient Care In The Clinic And Classroom." Journal of College Teaching and Learning 6 (2): 59-68. 